Submission ID: 43827

\title{
Prospective Hc-Bearing Objects in Western Part of Yenisei-Khatanga
} Regional Through

\section{S. Karpukhin* (SNIIGGiMS JSC)}

\section{SUMMARY}

Complex interpretation for the Yenisei-Khatanga regional trough was conducted using the latest available well and 2D-seismic data. As a result of work more than $20 \mathrm{HC}$ traps, falling into 3 categories (structural, structural-depositional and purely depositional), were identified. Traps are primarily associated with neocomian complex. Most traps are found to be purely structural and associated with inherited folds. These traps are accompanied by inverted circular structures (ICS) caused by low velocity anomalies (VAMP structures). Such features are clearly visible on time and flattened-time sections. For depositional traps localisation, strong correlation was found with thr geomorphology of pre-neocomian sea floor. Thickness maps for upper jurassic sediments were compiled to assist in delineating such depositional traps. Areal extent of tectonic-depositional traps appeared to be constrained by the northern part of the through. These traps are structural ones, but their closure in northern direction, which is critical due to the regional raising trend, is formed by the dipping clinororm beds. 


\section{Перспективные объекты западной части Енисей-Хатангского регионального прогиба}

\section{С.М. Карпухин* (АО "СНИИГГиМС")}

\section{Введение}

Изучаемая часть Енисей-Хатангского регионального прогиба расположена в пределах УстьЕнисейской и Енисей-Хатангской НГО Западно-Сибирской НГП и, в настоящее время, является одним из актуальных центров притяжения для поисково-оценочных работ на нефть и газ. Значительный интерес потенциальных инвесторов сформировался благодаря сходству строения и перспектив рассматриваемой области с близлежащими Гыданским и Большехетским НГР, близостью к Ванкорскому центру нефтегазодобычи, а также большому объему ГРР выполненных в регионе за государственный счет в течение последних 10 лет.

За последние годы в АО "СНИИГГиМС" были полностью аккумулированы все результаты и первичные материалы геологоразведочных работ последних лет. На базе современной изученности была проведена комплексная интерпретация данных ГИС (около 50 скважин), а также МОГТ-2D (более 35000 пог. км.), включая переобработанные с нуля и дообработанные архивные временные разрезы. В ходе работы были классифицированы типы нефтегазоперспективных объектов, основные из которых показаны графически, на Рис. 1. В докладе обсуждаются итоги выполненных работ, в том числе критерии выделения перспективных объектов и результаты их поиска.

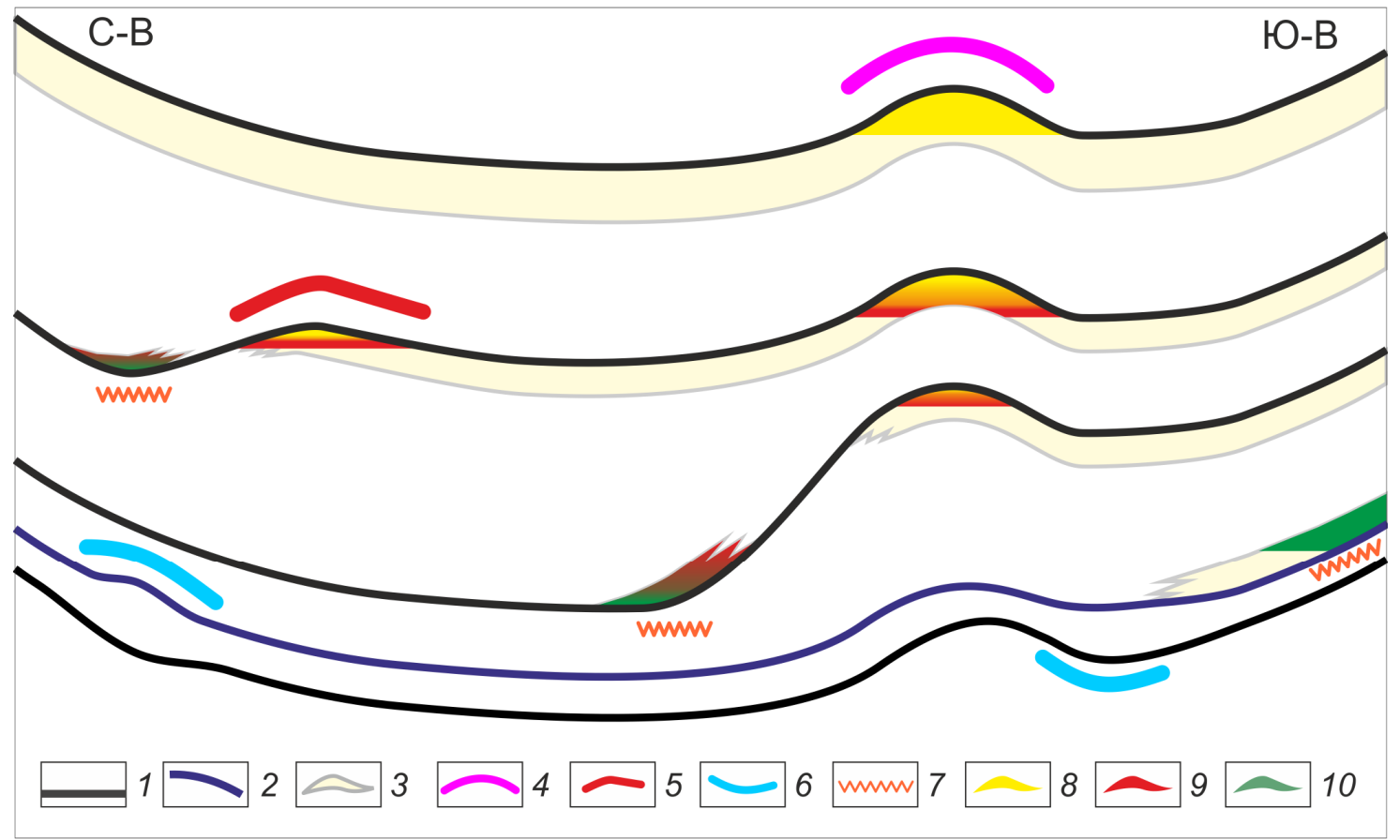

Рисунок 1 Схема размещения и типы ловушек УВ в неокомском клиноформном комплексе. 1 основные отражсающи горизонты; 2 - кровля юрских отложений (ОГ IIа); 3 - песчаниковые тела различного генезиса; 4 - унаследованные структурные ловушки; 5 - бескорневые (тектоно-седиментационные) ловушки; 6 - литологические ловушки; 7 - верхнеюрские субклиноформы; 8-газовые залежи; 9 - конденсатные залежи; 10 -нефтяные залежи.

Типы и примеры перспективных объектов по данным МОГТ.

В ходе анализа данных МОГТ-2D, в том числе и по уже открытым месторождениям, было отмечено, что практически все структурные объекты сопряжены с аномалиями «инверсия кольцевой структуры» (ИКС), то есть на временных разрезах и картах изохрон по горизонтам в 
меловом комплексе фиксируются положительные структуры, а при движении вниз по разрезу, их амплитуды убывают, вплоть до того, что по юрским ОГ наблюдаются уже отрицательные структуры. Интенсивность таких аномалий различна: на некоторых объектах наблюдается не полная инверсия, а только лишь незначительное уменьшение амплитуды с глубиной. Такие «слабые» аномалии ИКС, тем не менее, явно выражены при выравнивании на различные ОГ (например, ІІа в кровле юры). Аномалии подобных типов были зафиксированы впервые на севере Западной Сибири в середине 80-х годов XX века [1], практически сразу после начала широкого применения методики МОГТ. Для их объяснения предлагалось множество гипотез, однако наиболее распространённой точкой зрения является влияние низкоскоростных аномалий (VAMP) вследствие газонасыщения [3]. Эта гипотеза подтверждается, в частности, бурением на Хальмерпаютинской площади [3] и результатами обработки данных МОГТ с применением глубинной миграции до суммирования на Пякихинской площади [4]. Важно, что все объекты, сопряженные с инверсиями, представляют собой унаследованные структуры именно суммирование эффектов от многопластовых залежей приводит к значительным аномалиям в наблюдаемых $\mathrm{T}_{0}$ и в скоростях миграции. Например, инверсии сопутствуют таким месторождениям Танамской террасы как Ушаковское, Пеляткинское и Казанцевское, где интервал с установленной нефтегазоносностью превышает 500 метров, при том что мощности отдельных пластов составляют 10-50 метров. В тоже время на Дерябинском месторождении, несмотря на мощные (до 80 метров) газонасыщенные пласты HxIV-V (конуса выноса в фондоформной части неокомских клиноформ), инверсия на временных разрезах не наблюдается, так как залежи (и структуры) по другим уровням отсутствуют. Нанадянское месторождение Танамской террасы, изученное скважиной ННд-310, вскрыло лишь одну залежь (пласт Сд-0), однако, скважина находится в неоптимальных условиях (вблизи замыкания структуры), а реальный интервал газоносности, в замке структуры может быть значительно шире, аналогично Пеляткинскому месторождению. Бесспорная связь аномалий ИКС с месторождениями делает их важным прогнозным критерием, который может успешно применяться даже в условиях неоднозначности структурных построений. С опорой на аномалии ИКС на территории исследования было выявлено более 10 потенциальных объектов (Рис. 2). Пример аномалии типа ИКС для Нанадянского месторождения и потенциального объекта между Паютской и Яровской площадями приводится на Рис. 3

Помимо унаследованных структур на территории работ также выделяются тектоноседиментационные объекты. Это ловушки структурного типа, приуроченные к шельфовым частям клиноформ, в которых структурное замыкание в критическом направлении создается не за счет регионального тренда, а за счет перехода ундаформы в собственно клиноформу. Такие объекты возможны на северном борту прогиба (Рис. 2), где региональный тренд и тренд падения клиноформ разнонаправлены. Подобные объекты будут однопластовыми, и как следствие не будут сопровождаться инверсиями по подстилающим ОГ. Отсутствие инверсии, в таком случае, не говорит о безперспективности объекта.

Кроме рассмотренных объектов структурного типа, с которыми связаны, по большей части, газовые и газоконденсатные месторождения, на территории работ также распространены литологические объекты, для которых возможно нефтяное насыщение. В предшествующей работе, на примере Пайяхского нефтяного месторождения, была установлена тесная взаимосвязь между распространением коллекторов и палеоморфологией морского дна, на момент начала формирования неокомского комплекса [2]. Для этой части прогиба, области развития песчаниковых тел и литологические ловушки приурочены к зонам верхнеюрских палеоподнятий (уменьшенные мощности яновстанской свиты) Рис. 2. На базе полученных результатов прогнозируются залежи, аналогичные Пайяхскому месторождению Рис. 2, Рис. 4 (a). Аналогичные результаты были получены и для левобережья р. Енисей. Здесь потенциальные конуса выноса, определяемые на временных разрезах по характерным амплитудным аномалиям и «бугристой» волновой картине, приурочены к области развития верхнеюрской (гольчихинской) субклиноформы. Мощности выделенной юрской субклиноформы и потенциальные литологические объекты показаны на Рис. 2 , а визуализация одного из объектов на Рис. 4 (б) 


\section{EAGE}

EUROPEAN

ASSOCIATION OF

ENGINEERS

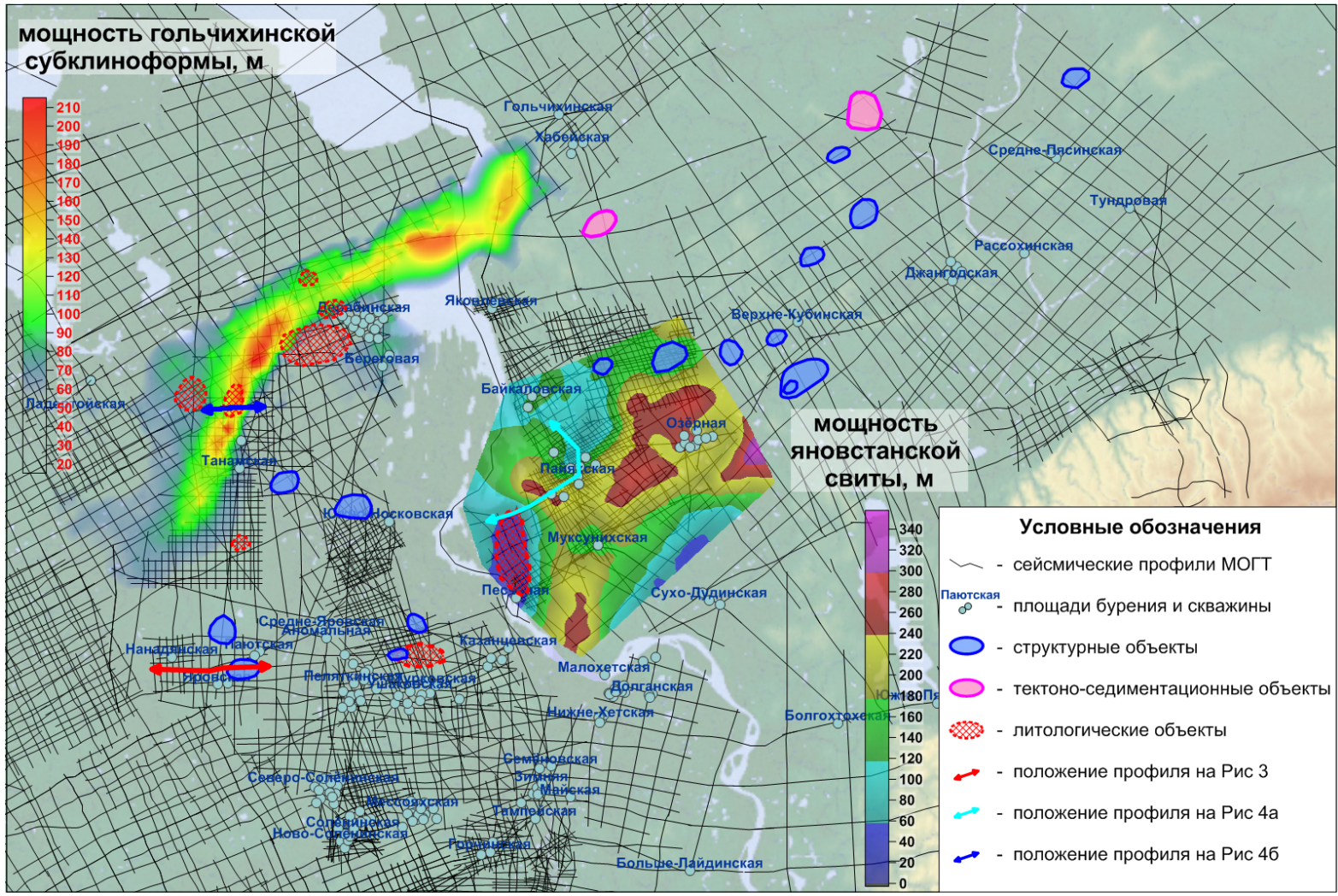

Рисунок 2 Перспективные объекты западной части ЕХРП

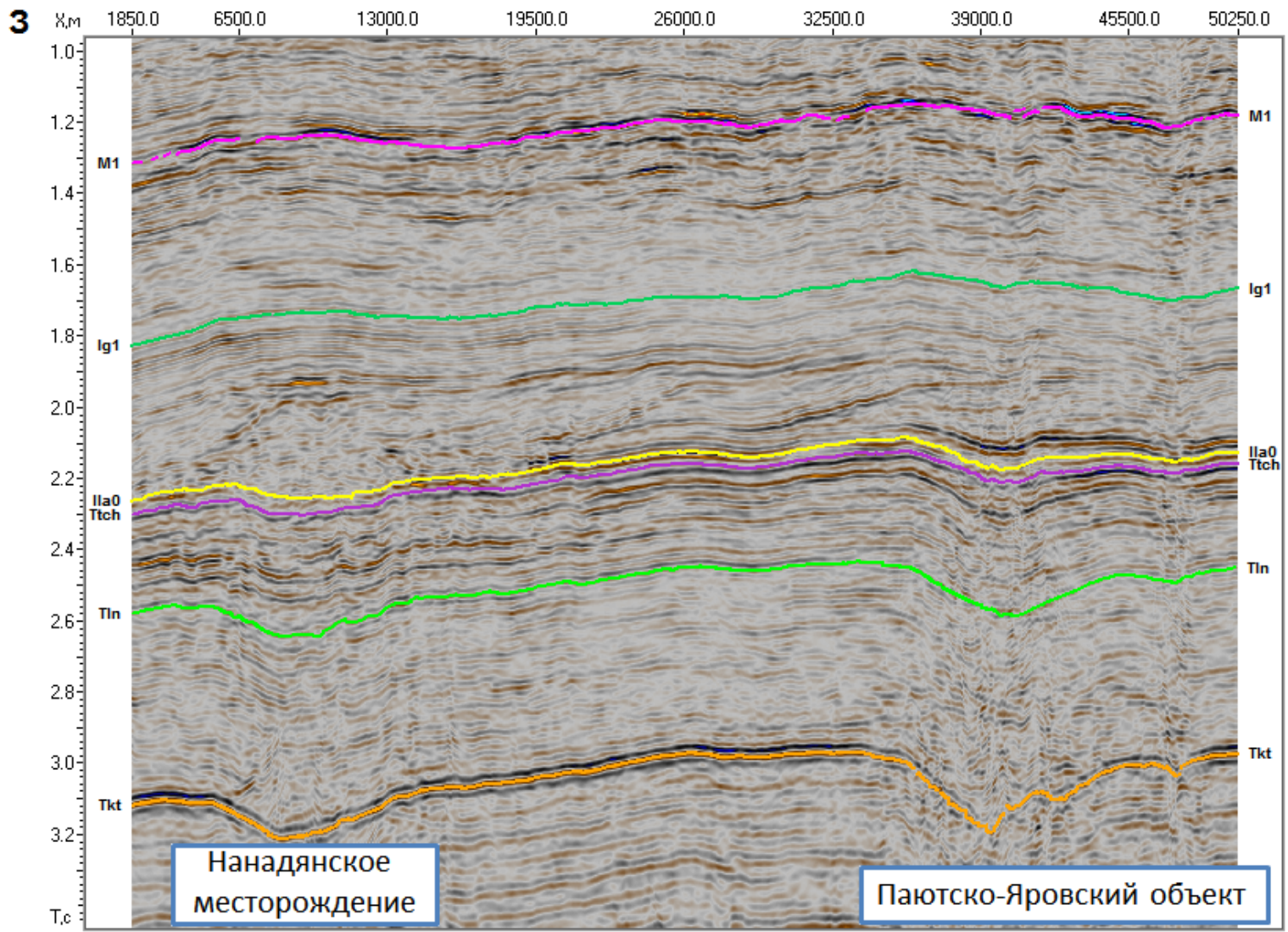

Рисунок 3 Визуализация структурных объектов, сопряженных с аномалиями ИКС 
ю. 3
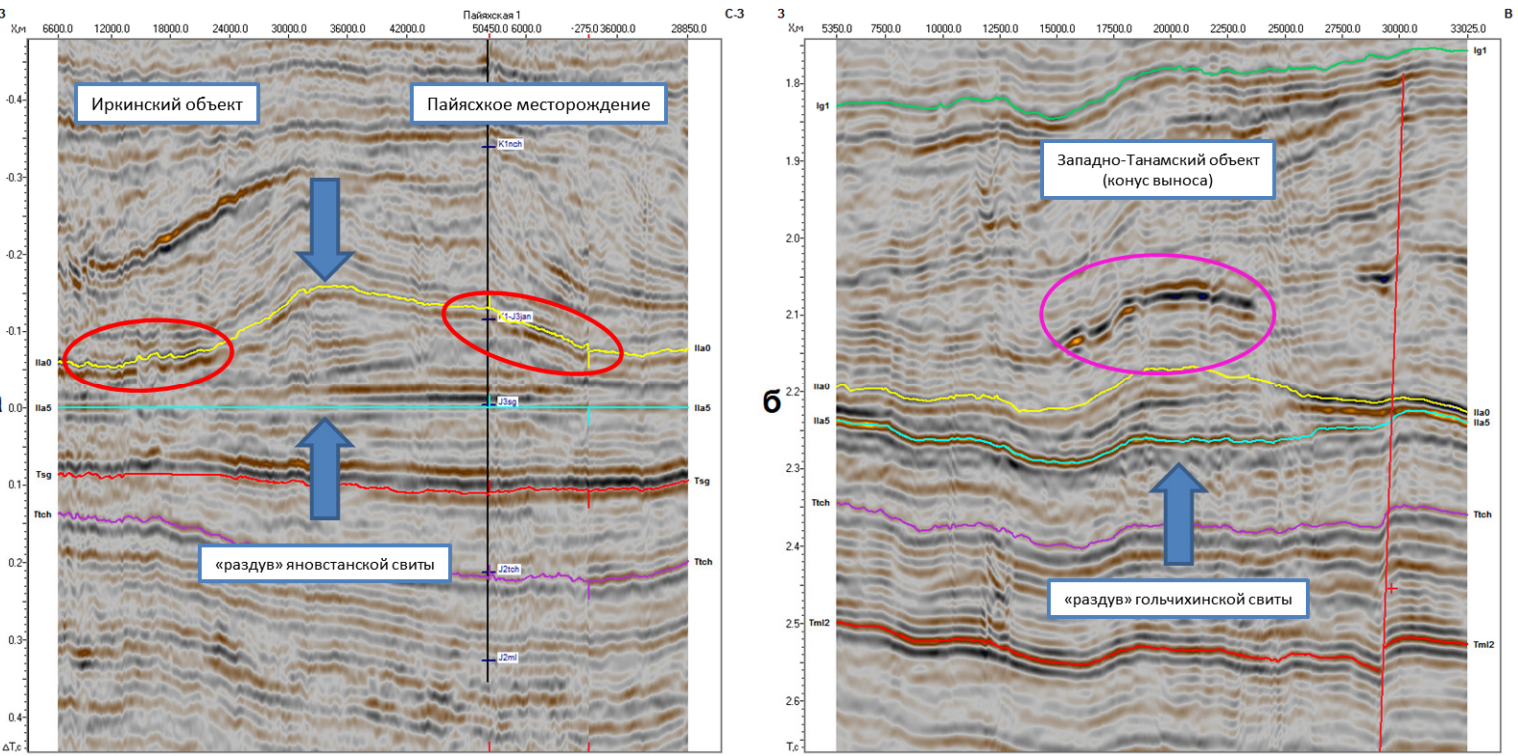

Рисунок 4 Визуализачия перспективных объектов ачимовского типа: (a) - в южной части прогиба, в правобережье р. Енисей; (б) - в северной части прогиба, в левобережье р. Енисей.

\section{Выводы}

На базе современной изученности западной части ЕХРП, по результатам комплексной интерпретации данных МОГТ-2D, и ГИС было выделено более 20 перспективных объектов структурного, структурно-литологического и литологического типов. Практически все открытые на территории ЕХРП месторождения и большинство неопоискованных объектов представляют собой унаследованные структуры, для выделения которых основным поисковым критерием являются аномалии типа ИКС (инверсионные кольцевые структуры). Большинство подобных объектов расположено на лицензированных территориях, приуроченных к окрестностям Танамской террасы и северо-западному окончанию Рассохинского мегавала. Расположение открытых залежей и предполагаемых литологических объектов (ачимовского типа) на территории ЕХРП тесно связано с палеоморфологией морского дна на конец юрского времени. В правобережье р. Енисей следует ожидать открытие нефтяных залежей, по типу Пайяхского месторождения, в первую очередь на Иркинском и Песчаном лицензионных участках. В левобережье р. Енисей, расположение выделенных конусов выноса, аналогов Дерябинского месторождения, тесно связано с гольчихинской субклиноформой. Потенциальные объекты этого типа расположены на территории Танамского участка и близлежащих нераспределенных землях. Перспективные тектоно-седиментационные ловушки обнаружены на северном борту прогиба, в правобережье р. Енисей, где учитывая слабую изученность, также возможны и пропущенные объекты.

\section{Библиография}

1.Гиршгорн Л.Ш., Кабалык В.Г. Поднятия чехла над глубинными кольцевыми депрессиями на севере Западной Сибири // Советская геология. - 1990. № 1. - С. 57-63.

2. Исаев. А.В., Кринин В.А., Карпухин С.М. Перспективы нефтегазоносности клиноформного комплекса Енисей-Хатангского регионального прогиба // Нефтегазовая геология. Теория и практика. - 2015. - Т.10. - №3. - http://www.ngtp.ru/rub/4/31 2015.pdf

3. Нежданов А.А., Огибенин В.В., Смирнов А.С. Нефтегазоносность Западно-Сибирского бассейна с позиций глубинного генезиса углеводородов // тезисы Всероссийской конференции по глубинному генезису нефти, 1-е Кудрявцевские чтения. - Москва. - ЦГЭ. - 22-25.10.2012 г 4. Обухова М.А., Кузнецов И.К., Миткалев Д.В., Качкин А.А., Сазыкин М.К. Прогноз поровых давлений на основе глубинно-скоростной модели в разрезе Большехетской впадины // тезисы конференции «Геомодель - 2015». - Геленджик. - 07-10.09.2015. 


\section{EAGE}

\section{Bibliography}

1.Girshgorn L.SH., Kabalyk V.G. Podnyatiya chekhla nad glubinnymi kol'cevymi depressiyami na severe Zapadnoj Sibiri // Sovetskaya geologiya. - 1990. № 1. - P. 57-63.

2. Isaev. A.V., Krinin V.A., Karpukhin S.M. Perspektivy neftegazonosnosti klinoformnogo kompleksa Yenisej-Khatangskogo regional'nogo progiba // Neftegazovaya geologiya. Teoriya i praktika. - 2015. - T.10. - №3. - http://www.ngtp.ru/rub/4/31_2015.pdf

3. Nezhdanov A.A., Ogibenin V.V., Smirnov A.S. Neftegazonosnost' Zapadno-Sibirskogo bassejna s pozicij glubinnogo genezisa uglevodorodov // tezisy Vserossijskoj konferencii po glubinnomu genezisu nefti, 1-e Kudryavcevskie chteniya. - Moskva. - CGE. - 22-25.10.2012 god

4. Obukhova M.A., Kuznetsov I.K., Mitkalev D.V., Kachkin A.A., Sazykin M.K. Prognoz porovykh davlenij na osnove glubinno-skorostnoj modeli v razreze Bol'shekhetskoj vpadiny // tezisy konferencii «Geomodel' - 2015». - Gelendzhik. - 07-10.09.2015. 